\title{
Elements of photovoltaic system design method
}

\author{
Bogdan Landowski ${ }^{*}$, Kamil Chisiński ${ }^{1}$, and Lukasz Muślewski ${ }^{1}$ \\ ${ }^{1}$ Bydgoszcz University of Science and Technology, Faculty of Mechanical Engineering, Al. prof. S. \\ Kaliskiego 7, 85-796 Bydgoszcz, Poland
}

\begin{abstract}
The study presents selected elements of a design method for renewable energy system based on photovoltaic technology. The main problems involved in the so called $500 \mathrm{~kW}$ photovoltaic farm are discussed. Examples of a few general concepts of photovoltaic farm systems are presented. Exemplary criteria for the concept selection are proposed. The main components to be used in a photovoltaic farm are presented, and some stages of the photovoltaic farm design are characterized.
\end{abstract}

\section{Introduction}

The beginning of photovoltaic technology dates back to 1839 , when A. E. Becquerela observed the impact of light on electrical properties of materials. In the next years, photovoltaic technology was significantly developed. In 1918 J. Czochralski innvented a method for obtaining metal monocrystals which contributed to development of photovoltaic cells based on silicon monocrystal technology. The first photovoltaic modules taking advantage of this technology were created in 1954 . Their efficiency was $4.5 \%$. Nowadays, the standard efficiency of photovoltaic panels of crystalline silicon based photovoltaic panels is $12-18 \%$. At the beginning of the 2000 s people started to pay special attention to the ecological issues including environment protection and air pollution reduction. Along with the development of people's awareness of the impact of industry and fossil fuel exploitation on the environment, numerous actions have been taken to stop devastation of the earth and its atmosphere. Development of renewable energy is one of the sustainability rules. Thus, in Poland and in Europe, numerous renewable energy systems have been created. In Poland, in 2019 , the energy from renewable sources accounted for $12.18 \%$ percent of the total gross domestic energy consumption. The biggest share was on the part of solid biofuels $(65.56 \%)$, liquid biofuels (10.36\%) and wind farms $(13.72 \%)$ [3].

The study deals with the problems connected with the rules of a photovoltaic system design. Photovoltaic farms are technical objects whose purpose is to produce electrical energy from the sun radiation.

Efficient use of such systems requires application of adequate operation strategies. Diagnostic processes are a significant group of operation and maintenance processes for

*Corresponding author:Bogdan.Landowski@pbs.edu.pl, bl-sluzbowy@wp.pl 
machines and many other devices [4-7]. To provide photovoltaic systems with the possibility of electrical energy effective production, many maintenance, diagnostic and monitoring operations are needed.

Hence, appropriate design of this type of systems is an important issue both in terms of ecology, economy and technology.

Appropriate design of a photovoltaic system requires, among others, selection of a suitable location, appropriate elements and protection systems which are necessary for efficient operation and maintenance of the photovoltaic farm equipment. The article deals with the problems associated with a design of $500 \mathrm{~kW}$ photovoltaic farm.

Design of energy systems involves analyses of not only economic aspects including its construction, operation and maintenance costs but also the issues of safety, reliability, availability, etc.An energy system can be treated as a complex operation and maintenance system which uses technical objects such as: devices for power production and power transformation, transmission lines and others.

Operational efficiency o electrical power systems and technical objects used in these systems can be analyzed like other public service systems in economic and technological terms [7-9].

Assessment, analysis and prognosis of reliability and efficiency of photovoltaic systems is connected with mathematical modeling of operation and maintenance of technical objects of the same class [11-14].

Due to random character of technical object state changes, modeling of operation and maintenance processes is commonly performed with the use of stochastic processes $[9,13-$ $16]$.

A natural model of the operation and maintenance process is random process $\mathrm{X}(\mathrm{t})$ with a finite number of $\mathrm{S}$ space states and a set of $\mathrm{R}+$ parameters (subset of real numbers $\geq 0$ ). Markov and semi Markov process theory are used for mathematical modeling of operation and maintenance processes of many technical objects[10, 13-18].

In the area of technical sciences, stationary and homogeneous Markov processes are used, among others, for construction of reliability models of inventory systems, spare part stock management risk and modeling of the processes of technical object state changes. $[10,13]$.

Markov models are used, among others, for determination of an optimal number of backup objects [15]. In this area of optimization, an objective function in the form of minimization of the costs involved in application of a backup system and downtimes is most commonly used as well as the method for analysis of costs and benefits associated with the use of the backup objects.

Currently, attempts are undertaken to increase the share of electrical energy in the so called energy mix as an alternative to other energy forms. Electric cars are the examples whose one of aims is to replace petroleum with electrical energy as a new form of fuel. At the present stage of technological development, electrical vehicles are burdened with one significant disadvantage, that is, relatively short distance that an electric car can cover (fully charged) as compared to gas powered vehicles. Therefore, experiments connected with production of self-charging vehicles using photovoltaic panels are being carried out. It needs to be noted that tests on application of the so called biofuels and mixtures of diesel fuel with bio additives as alternatives to fossil fuels are still being conducted $[17,18]$.

For determination of the values and performance of technical and economic assessment of technical objects used in complex operation and maintenance systems including photovoltaic ones, it is necessary to acquire and process data on the system operation and maintenance. For this purpose, it is necessary to conduct tests in a real technical object [4, 7$10,12,19-23]$. 


\section{Design assumptions}

Design of a photovoltaic system is a multi-stage process which requires from the designer to use his/her knowledge and apply an efficient

Design of a photovoltaic system is a multi-stage process which requires from the designer to use his/her knowledge and apply an efficient method of design and selection of its elements. Formalized procedures need to be used in each phase of the design. Selection of each significant element of the photovoltaic farm should be substantively justified. This kind of system needs to be provided with safety and protection devices, and the conditions of safe operation of its elements are found to be crucial. It is necessary to prepare respective technical documentation.

Below, there are the accepted initial assumptions of the design.

It is assumed that the analyzed photovoltaic system will be connected to the power grid. The rated power is $500 \mathrm{~kW}$. The estimated size of the construction area should be from 15 $000 \mathrm{~m}^{2}$ to $45000 \mathrm{~m}^{2}$,depending on the method of photovoltaic panel spatial arrangement. Photovoltaic panels should be south - facing and fixed in a stationary manner. The racking and tracking systems must be set in concrete foundations. The minimal distance of photovoltaic panels from the earth surface is from 1.00 to1.25 meters [24, 25].

\section{Concepts of the design solutions}

Three photovoltaic farm design concepts have been proposed. They are called concept A, B and $\mathrm{C}$, respectively. These concepts differ mainly in the power of photovoltaic panels, the number of inverters and the photovoltaic panel installation manner.

\subsection{Concept A}

Concept A assumes that a photovoltaic farm consists of 2000 photovoltaic panels of $250 \mathrm{~W}$ power, $500 \mathrm{~kW}$ central inverter and a direct current switchboard. Photovoltaic panels of such power are widely used and offered by different photovoltaic firms. This solution includes connected in series photovoltaic panels which enables chain connection of photovoltaic panels. In this type of connection, the voltage in each switchboard is equal to the voltage of a single chain (the sum of voltages of all photovoltaic panels of the chain), the value of current supplied to each switchboard is equal to the sum of all currents of photovoltaic panels in chains connected to the switchboard (the current flowing in a chain is equal to the current of a single photovoltaic panel). On the inverter input, however, the voltage value is equal to the voltage of a single switchboard, the current is equal to the sum of currents of each of the connected switchboards. Foundations of the photovoltaic farm elements are set in the ground and covered with concrete. Photovoltaic panels are mounted on metal racks, at the height from 1 do 1.1 meters above the surface. Electrical cables are placed in the ground at the depth from 0.2 to 0.3 meters from the ground freezing zone. The estimated area of the photovoltaic farm is $20500 \mathrm{~m}^{2}$ with a margin of $-5 \%$ and $+15 \%$ where the minimal length of the side must be 190 meters $[24,25]$.

According to concept $\mathrm{A}$, the photovoltaic system is divided into 8 segments. Each segment includes one eighth of all photovoltaic panel chains and a direct current switchboard. Each switchboard is connected to the inverter and the inverter to the power grid. The arrangement of a photovoltaic system according to concept $\mathrm{A}$ is presented in figure 1 . A scheme of a single segment of photovoltaic farm according to concept $\mathrm{A}$ is shown in figure 2 . 


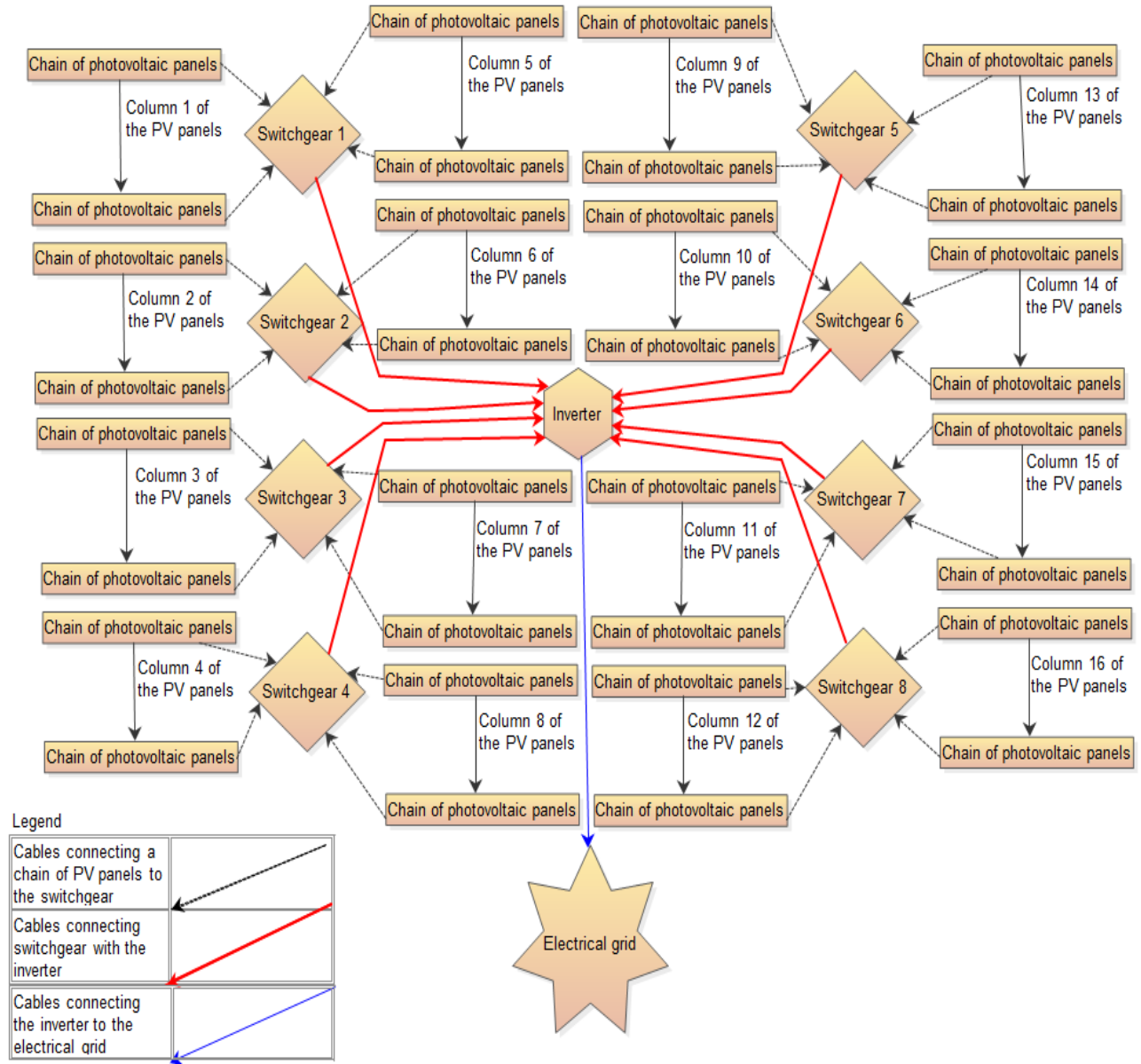

Fig. 1. Block scheme of photovoltaic farm according to concept A (own study).

Column m

Column $\mathrm{m}+1$

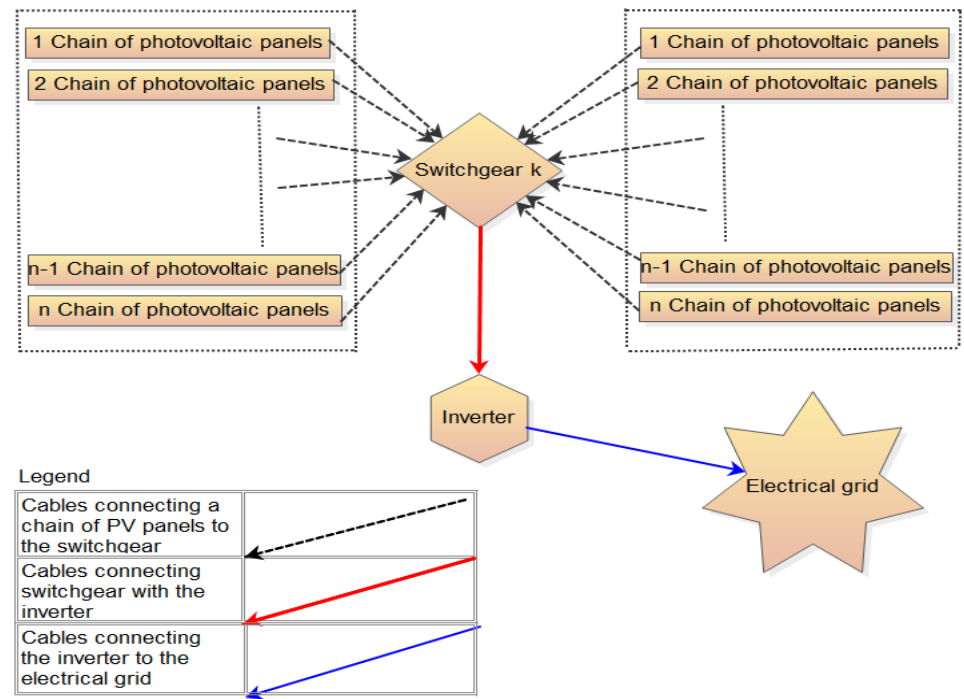

Fig. 2. Scheme of a single segment of a photovoltaic farm according to concept A (own study). 


\subsection{Concept B}

According to concept $\mathrm{B}$, a photovoltaic farm consists of $1667300 \mathrm{~W}$ photovoltaic panels, five $100 \mathrm{~kW}$ inverters and direct current switchboards. This solution involves a parallel connection of photovoltaic panels, thus reducing the number of photovoltaic panels in the system and increasing the power of a single panel which causes a decrease in the photovoltaic system voltage. The power of $300 \mathrm{~W}$ is one of the higher power values of standard photovoltaic modules. Due to such a connection, the voltage that occurs in each electric switchboard is equal to the voltage of a single panel, and the value of current supplied to each switchboard is be equal to the sum of all currents of photovoltaic panels connected to the switchboard. However, the value of voltage at the input of each inverter is equal to the voltage of a single switchboard, and the value of current is equal to the sum of currents of each connected electric switchboard. The foundations of the photovoltaic farm elements are set in the ground and reinforced with concrete. Photovoltaic panels are installed on metal racks in two rows, at the height from 1.0 to 1.1 meters above the surface. Electrical cables are placed on the ground, at the depth from 0.2 to 0.3 meters from the ground freezing zone. The estimated area of the photovoltaic farm is $28500 \mathrm{~m}^{2}$ with a margin $-10 \%$ and $+10 \%$ where the minimal length of the side must be 50 meters [24, 25].

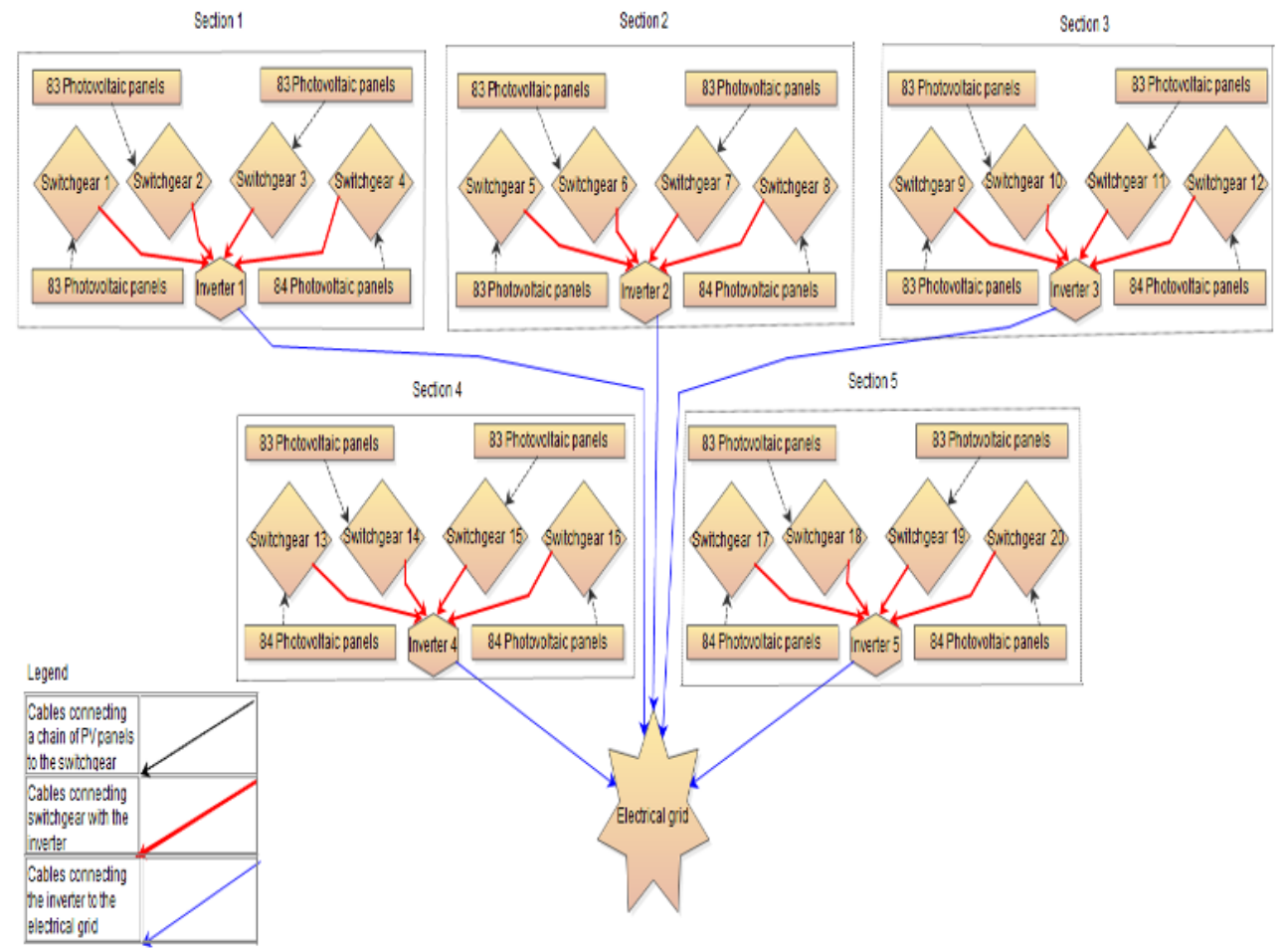

Fig. 3. Block scheme of photovoltaic farm according to concept B (own study).

According to concept $\mathrm{B}$, the photovoltaic system is divided into 5 segments. Each segment contains 333 or 334 photovoltaic panels, 4 direct current switchboards and an inverter. 83 or 84 photovoltaic panels are connected to each switchboard. Each switchboard is connected to an inverter and the inverters to the power grid. Arrangement of the photovoltaic farm according to concept $\mathrm{B}$ is presented in figure 3. A scheme of a single segment according to B concept is shown in figure 4 . 


\section{Section $m$}

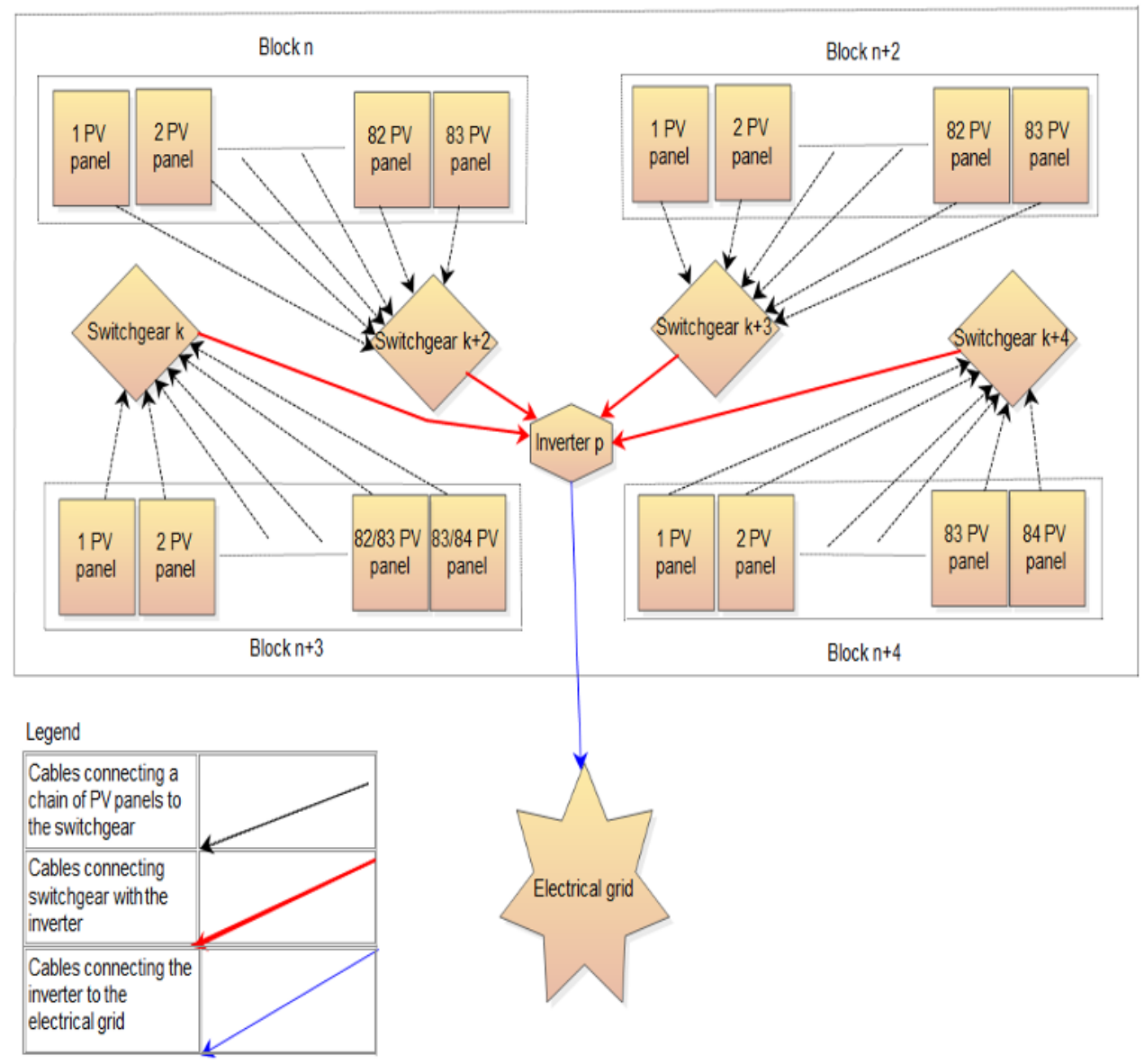

Fig. 4. Scheme of a single segment of a photovoltaic farm according to concept B (own study).

\subsection{Concept C}

According to concept C, a photovoltaic farm consists of $1252400 \mathrm{~W}$ photovoltaic panels, 250 tracking systems, $2502 \mathrm{~kW}$ inverters and an alternative current switchboard. In this solution, the voltage on the inverters is equal to the voltage of a single photovoltaic panel, and the flowing current is equal to the sum of currents of the photovoltaic panels connected to the inverter. The voltage supplied to the switchboard is equal to the voltage on the inverter and the current flowing to the switchboards is equal to the sum of currents supplied to the inverters. The power of $400 \mathrm{~W}$ is one of the highest values of standard photovoltaic module models. Since the photovoltaic panels are installed on a tracking system, their power should be as high as possible to reduce the number of photovoltaic panels in the system, and subsequently, the number of tracking systems to be required. Foundations of the photovoltaic farm elements are set on the ground and covered with concrete. The electrical cables are placed in the ground, at the depth from 0.2 to 0.3 meters from the ground freezing zone. The estimated area of the photovoltaic farm is $43000 \mathrm{~m}^{2}$ with a margin $-5 \%$ and $+5 \%$ where the minimal length of the side must be 150 meters [24, 25].

According to concept $\mathrm{C}$, the photovoltaic system is divided into 5 segments. Each segment consists of 50 sets and 1 alternating current switchboard. Each set includes 4 
photovoltaic panels, 1 tracking system and 1 inverter. 50 sets will be connected to each switchboard, and 4 photovoltaic panels is connected to each inverter. Each switchboard is connected to the power grid. The arrangement of $\mathrm{C}$ concept photovoltaic farm is presented in figure 5. The scheme of a single set of the photovoltaic farm according to concept $\mathrm{C}$ is shown in figure 6 .

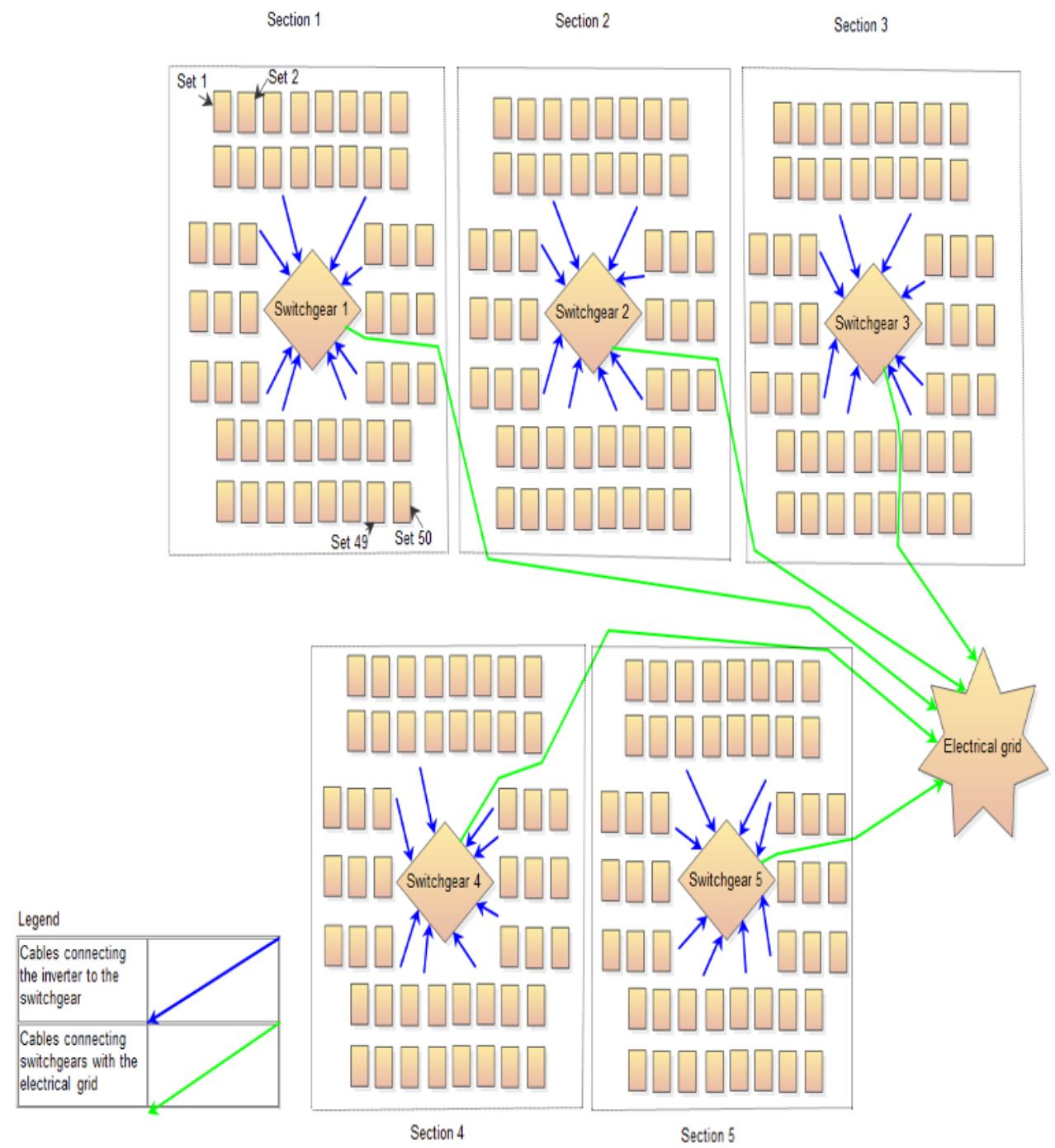

Fig. 5. Block scheme of photovoltaic system according to concept $\mathrm{C}$ (own study). 

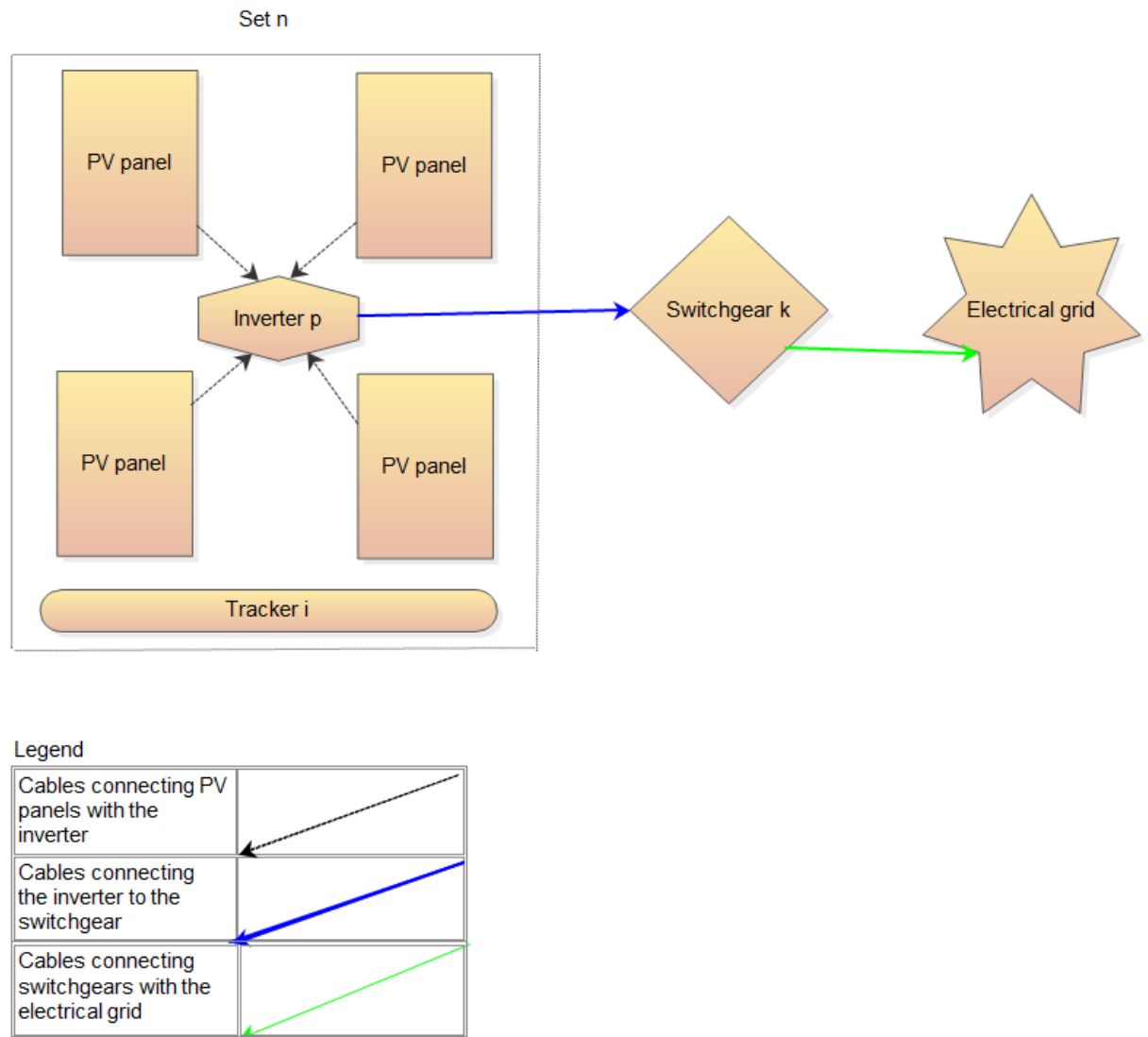

Fig 6. Scheme of a single set of a photovoltaic farm according to concept C(own study).

\section{Selection of elements to be used in the photovoltaic system}

The next step of the design process is selection of one of the developed concepts to provide the basis for further analysis. In order to choose a concept and match the elements, a set of criteria for assessment of the analyzed solutions was developed. Weights were assigned to the criteria. Both the assignment of weights to the criteria and the assessment were performed by a group of experts.

According to a multi-criteria analysis, concept A was found to be the best to satisfy the accepted criteria, therefore, it was chosen for further consideration. The assessment involved, among others, such criteria as: photovoltaic panel power, the method for connection of photovoltaic modules, the number of switchboards, the number of inverters, occurrence of tracking systems, the operation and maintenance issues, installation, the impact of external factors, initial estimation of financial and other inputs.

The next step involved choosing a photovoltaic panel. For this purpose, several models of photovoltaic panels were analyzed. The analysis covered the values of the panel major characteristics, which were evaluated according to the developed system of criteria. The analyzed characteristics included both electric and mechanical parameters of the photovoltaic panel. The value of voltage, current, power, efficiency and temperature coefficients are significant parameters of photovoltaic panels. Moreover, the values of geometric features of photovoltaic panels were analyzed as well as their mass, number of links, and the connection method and the number of side diodes. When choosing photovoltaic panels, one should take into consideration the manufacturer and the warranty period. 
It was Senersum SSM92A-250 photovoltaic panel that was accepted for further analysis.

The next element to be chosen for the designed photovoltaic farm system is an inverter. It was chosen according to an earlier developed procedure, that is, analogically to the above described method of choosing photovoltaic panels. The major electrical parameters of the inverter to be analyzed are the values of power, efficiency and minimal and maximal current at the input. Other parameters to be analyzed are the dimensions of the inverter sides, its mass and the number of input connections. When choosing an inverter, it is recommended to take into consideration the manufacturer and the scope of the operational temperature.

The inverter power should not be smaller than $70 \%$ and or higher than $120 \%$ of the power of the whole photovoltaic farm [25].

Inverter of SMA company, S.C.-500CP-US model was accepted for further analysis.

In the analyzed design concept, photovoltaic panels are connected to each other in chains. To determine the number of photovoltaic panels, appropriate calculations need to be performed. Based on the calculations, it was found that the system would consist of 145 photovoltaic panel chains including 12 photovoltaic panels and 20 photovoltaic panel chains consisting of 13 photovoltaic panels. The calculated current generated from all photovoltaic panel chains is smaller than the maximal input current of the selected inverter [24].

Work [24] shows calculations that should be used for choice of particular elements of the designed system and characteristics of the designed photovoltaic panel elements.

\section{Conclusions}

The study presents selected elements of the method for design of a renewable energy system, on the basis of photovoltaic technology. The basic issues concerning selected aspects of the design of the so called $500 \mathrm{~kW}$ photovoltaic farm have been discussed.

The idea of the procedure developed for choosing the best photovoltaic farm design and selection of the most important elements to be used in it has been presented. A system of assessment criteria with weights assigned to them is an element of this procedure.

A large photovoltaic system often consists of thousands of parts, starting with photovoltaic panels and finishing with fuses and electrical cables. The bigger the number of elements the higher the risk of its damage which can cause disruption of the system operation or deterioration of its efficiency. Hence, it seems advisable to use models of the operation and maintenance processes for this type of system including the stage of design.

Elements of photovoltaic systems undergo constant modernization. The development of photovoltaic technology is very dynamic. Therefore, design of such systems requires predicting value changes of the system element characteristics in terms of technological progress and environmental changes, including formal-legal regulations on this kind of investments, which may be of great importance for economic efficiency of the undertaking.

\section{References}

1. Ł. Antczak, P. Berliński, S. Górka, K. Jankowski, W. Kryłłowicz, M. Sibiński, I. Wasiak, K. Znajdek, Renewable Energy Sources Selected Issues, Łódź, Polska (2014)

2. A. Mroziński, J. Flizikowski, Photovotaic Engineering of Photovoltaic Systems, Bydgoszcz, Polska (2016)

3. Central Statistical Office (GUS), Energy from renewable sources 2019 r.https://stat.gov.pl/files/gfx/portalinformacyjny/pl/defaultaktualnosci/5485/10/3/1/energ ia_ze_zrodel_odnawialnych_w_2019.pdf (12.10.2021)

4. T. Kałaczyński, M. Łukasiewicz, J. Musiał, R. Polasik, M. Szczutkowski, N. Dluhunovych, J. Wilczarska, T. Kasprowicz, Analysis of the diagnostic potential 
research thermovision in the technical state of combustion engine injectors assessment. Engineering Mechanics 2018, 24nd International Conference, 1805-8248, 1417.05.2018 Svratka, Czech Republic (2018)

5. M. Łukasiewicz, P. Falęcki, T. Kałaczyński, B. Żółtowski, J. Musiał, J. Wilczarska, R. Kostek, Analysis of the thermovision diagnostics potential in the light system elements, Engineering Mechanics 2018, : Institute of Theoretical and Applied

6. M. Łukasiewicz, T. Kalaczynski, J. Musial, J. Shalapko, Diagnostics of buggy vehicle transmission gearbox technical state based on modal vibrations, Journal of Vibroengineering, Volume 16, Issue 6, pp. 3137-3145 (2014)

7. V. Martynyuk, O. Eromenko, J. Boiko, T. Kałaczyński, Diagnostics of supercapacitors, 17th International Conference Diagnostics of Machines and Vehicles, Matec Web of Conferences2018, 182, pp. 1-10 (2018)

8. Ł. Muślewski, L. Knopik, B. Landowski, O. Polishchuk, Analysis of assessment criteria for selected systems of transport means operation, MATEC Web of Conferences 182, 02003 (2018), 17th International Conference Diagnostics of Machines and Vehicles, pp.1-10 (2018), https://doi.org/10.1051/matecconf/201818202003

9. B. Landowski, Ł. Muślewski, M. Pająk, O. Polishchuk, Method for initial assessment of unit costs of public city transport means operation, MATEC Web of Conferences 182, 01010 (2018), 17th International Conference Diagnostics of Machines and Vehicles, pp.1-7 (2018), https://doi.org/10.1051/matecconf/201818201010

10. B. Landowski, D. Perczyński, P. Kolber, Ł. Muślewski, An example of Markov model of technical objects maintenance process. Engineering Mechanics 2016, 22nd International Conference, may $9-12$, 2016, Svratka, Czech Republic, Book of full texts, Institute of Thermomechanics Academy of Sciences of the Czech Republic, pp. 346-349 (2016)

11. B. Landowski, D. Perczyński, Ł. Muślewski, P. Kolber, Economic aspects of a city transport means purchase. Proceedings of 58th International Conference of Machine Design Departments - ICMD 2017, Publisher: Czech University of Life Sciences Prague, Czech Republic, pp. 194-199 (2017)

12. B. Landowski, $Ł$. Muślewski, Numerical simulation of stochastic process as a model of technical object state changes. Engineering Mechanics 2018 Proceedings, Vol 24 Book Series: Engineering Mechanics, 24nd International Conference, may 14 - 17, 2018, Svratka, Czech Republic, Book of full texts, Institute of Theoretical and Applied Mechanics of the Czech Academy of Sciences, Prague, pp. 485-488 (2018)

13. N. Buslenko, W. Kalasznikov, I. Kovalenko, Theory of complex systems(Theory of complex systems), PWN, Warszawa (1979)

14. B. Landowski, $Ł$. Muślewski, Decision model of an operation and maintenance process of city buses, Proceedings of 58th International Conference of Machine Design Departments - ICMD 2017, Publisher: Czech University of Life Sciences Prague, Czech Republic, pp. 188-193 (2017)

15. Hamoud G. A.: Use of Markov Models in Assessing Spare Transformer Requirements for Distribution Stations, in IEEE Transactions on Power Systems, vol. 27, no. 2, pp. 1098-1105, May 2012, doi: 10.1109/TPWRS.2011.2177999

16. M. L. Puterman, Markov decision processes, John Wiley, New York (1994)[22]

17. M. Markiewicz, Ł. Muślewski, M. Pająk, Impact Of Biocomponent Additive To Diesel Oil On Values Of Elected Functional Parameters Of Transport Means, Polish Journal Of Environmental Studies, Vol. 29, (2020) 
18. M. Markiewicz, Ł. Muślewski, Survey performance and emission parameters of diesel engine powered by diesel oil and fatty acid methyl esters using fuzzy logic techniques, Fuel, Vol. 277, (2020)

19. P. Kolber, D. Perczyński, K. Peszyński, B. Landowski, Efficiency testing of thermoelectric cooling cell based on peltier module. Engineering Mechanics 2018 Proceedings, Vol 24 Book Series: Engineering Mechanics, 24nd International Conference, may $14-17,2018$, Svratka, Czech Republic, Book of full texts, Institute of Theoretical and Appiled Mechanics of the Czech Academy of Sciences, Prague, pp. 381 384 (2018)

20. P. Kolber, D. Perczyński, B. Landowski, S. Wawrzyniak, The control system of the stepper motor motion with positioning accuracy verification. Engineering Mechanics 2016 Proceedings, Vol 22 Book Series: Engineering Mechanics, 22nd International Conference, may 9 - 12, 2016, Svratka, Czech Republic, Book of full texts, Institute of Thermomechanics Academy of Sciences of the Czech Republic, pp. 298-301 (2016)

21. B. Landowski, Application of Markov decision process as a mathematical model of operation and maintenance process. p-ISSN: 1733-8670. Scientific Journals. Maritime University of Szczecin, 2010, 24(96) pp. 12-16 (2010)

22. B. Landowski, M. Baran, Analysis of selected results of engine oil tests, MATEC Web of Conferences 302, 01010 (2019), 18th International Conference Diagnostics of Machines and Vehicles, pp.1-7 (2019)

23. B. Landowski, M. Baran, Analysis of changes in the value of selected lubricant characteristics during use, MATEC Web of Conferences 302, 01009 (2019), 18th International Conference Diagnostics of Machines and Vehicles, pp.1-8 (2019)

24. K. Chisiński, Concept of photovoltaic farm, bachelor's thesis, suprervisor B. Landowski, University of Science and Technologyin Bydgoszcz, Faculty of Mechanical Engineering, Bydgoszcz, Poland (2020)

25. J. Korczyński, How to construct a photovoltaic farm, Lublin, Poland (2015)

26. M. Szyca, J. Musiał., Analysis of the BMA K2400 Vertical Centrifuge Turbine in terms of balancing and vibration diagnostics, Herald of Khmelnytskyi National University Technical Sciences 297(3), 71 (2021), doi: 10.31891/2307-5732-2021-297-3-71-80.

27. S. Horiashchenko, K. Horiashchenko, J. Musiał, Methodology of measuring spraying the droplet flow of polymers from nozzle. Mechanika 2020, 26, 82-86 